\title{
REAL-TIME GENERATOR FUEL LEVEL MEASUREMENT METER WITH ULTRASOUND SENSOR AND DATA ACQUISITION SYSTEM
}

\section{T. DHANYA}

Department of Electrical and Electronics Engineering (Marine), AMET University, Tamil Nadu, India

The usage of Generator has changed into an especially standard in each useful sense each lethargic establishment affiliations, Industries, centres, Townships et cetera, while by using these Generators, assorted bothers are restricted by the customers and associations. Among each other test fuel taking from the generator fuel tank has changed into an abrading issue as the cost of the fuel is touching out of this world especially asked. Disregarding the way that various security and achievement parts are joined the fuel burglary yet is so far insane, and the loss of the affiliations is interminable. So a pushed control structure is composed with the PIC microcontroller which can gauge the level of fuel in the fuel tank by using a creative ultrasound sensor and store the data into an obtaining data system.
\end{abstract}

KEYWORDS: Real Time Clock; I2C; PIC; RS232 One Wire Communication

Received: Oct 06, 2017; Accepted: Oct 26, 2017; Published: Jan 30, 2018; Paper Id.: IJMPERDFEB2018105

\section{INTRODUCTION}

With the modernisation of progress, a generator has turned into a vital piece of energy era source. At any time of power emergency like severe climate or power cut due to power lack a generator is winding up plainly most stable wellspring of energy shape massive industry to any little condo A new-type sensor for monitoring oilwater interface level and oil level is illustrated in (G. Lu, et al., 2009), (J. Kim and S. Park, 2012), (E. Terzic et al., 2012) is explained in Neural Network Approach to Fluid Quantity Measurement in Dynamic Environments. Standby power era is a vital segment of a high accessibility control framework for server farms and system rooms where generator structures with diesel or flammable gas motors are the best arrangement as with battery just brief time of energy supply is conceivable (E. Terzic, et al., 2010) is narrated in Capacitive sensor-based fluid level measurement in a dynamic environment using neural network.

Presently a-days generator establishment and its upkeep turn into a major issue as more often than not generators are situated in remote spots. Albeit every one of the topics are disturbing and can be given most significance however in this venture work the inclination is given to the unforeseen issue that is fuel robbery from the fuel tank of a generator as a significant portion of the generator organizations are tallying lost a great many monetary forms as a result of this surprising fuel misfortune. Diesel burglary is a global issue, with news of fuel robbery are originating from the present day nations like Australia, the UK and New Zealand and also over the US and in the creating countries like India, Bangladesh and so forth fuel taking rate is unbelievably high (M. E Erdem and D Guns, 2011) is presented in Liquid level sensor in automotive design, sensor come. With the expanding price of fuel, this issue of fuel robbery has turned into a noteworthy inconvenience for the proprietor of various generator organisations. New cryptography algorithm with for efficient data communication is described in (GaneshKumar, K., Arivazhagan, D., 2016). K-strange points clustering algorithm, and survey of big data 
analytics in healthcare and government is presented in (Johnson, T. and Singh, S.K., 2015), (Archana, J. and Anita, E.M., 2015). Current channelling in time-domain airborne electromagnetic data is discussed in (Reid, J., \&Macnae, J. 2000). Fast AEM data processing and inversion are described in (B. Thangalakshmi, Nov 2013).

\section{WORKING PRINCIPLE}

The system contains an Ultrasound Sensor Module, Liquid Crystal Display (LCD) to demonstrate the updates, a smaller scale SD card for information Procurement and Real Time Clock (RTC) to give precise time and date. Two PIC microcontrollers $18 \mathrm{~F} 4520$ controls the entire system.

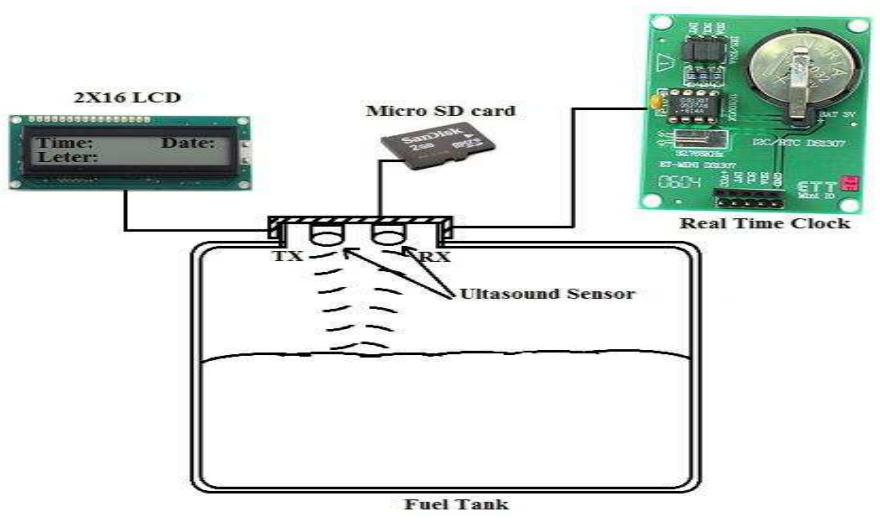

Figure 1: System Overview

This system contains two 18F4520 PIC microcontrollers that are related using RS232 one wire tradition through TX, and RX stick of port C. Starting 18F4520 IC includes an LCD to show time, Date and Fuel level, and it is interfaced in port B of PIC. RTC DS1307 is interfaced in port C, and setting switches are related in port D. TS601, the ultrasound module is interfaced in RD0. The data of time, date, and fuel level is traded to another 18F4520 through a string. Littler scale SD card connector is related to the port $\mathrm{C}$ of that microcontroller and data is secured with the prompt line in the memory contraption. Settings option is endorsed by using a submitted mystery key for every last contraption.

\section{RESULTS AND DISCUSSIONS}

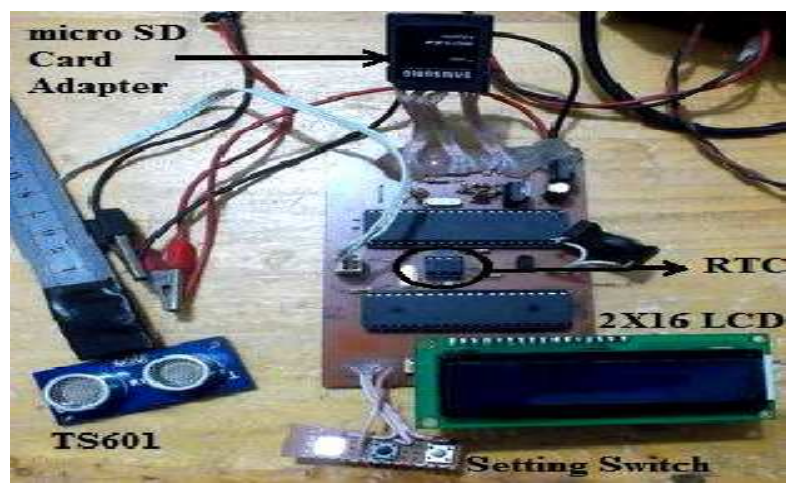

Figure 2: Hardware Implementation

Figure 2 shows that the password option of the implemented system to enter in the settings option. And apply the tank size measurement option to calibrate the fuel level amount and the measurement of fuel by using the ultrasound sensor. 


\section{CONCLUSIONS}

As the fuel robbery is changing into an essential issue for the generator affiliations, this masterminded gadget can be a real blue helping for the proprietors of those associations. Despite the way that the present sensors like capacitance sensor display in the market can give security from the outside traps however those can't guarantee the safety of the fuel tank from the inside tricks of the affiliations. By introducing this fuel meter in the fuel tank, the membership association can efficiently track that how much fuel is reloaded in the reservoir and what entirety is utilised each moment as the downsized scale SD card will store information taking following a change of a moment. Settings choice is also secured through a watchword so that nobody however basically the insisted individual can change the settings. So in the period of high fuel regard, the generator affiliations can keep fuel robbery from the hand of their particular staffs by utilising this advancing fuel estimation meter. This entire structure is compelling, right and inconsequential effort additionally.

\section{REFERENCES}

1. G. Lu, et al., (2009) A new-type sensor for monitoring oil-water interface level and oil level.

2. J. Kim and S. Park, (2012) A study on sensor design for measurement of automobile engine oil degradation and level.

3. E. Terzic et al., (2012) Capacitive Sensing Technology, Chapter: 2, A Neural Network Approach to Fluid Quantity Measurement in Dynamic Environments.

4. E. Terzic, et al., (2010) Capacitive sensor-based fluid level measurement in a dynamic environment using a neural network.

5. M. E Erdem and D Guns, (2011)Liquid level sensor in automotive design, sensor come.

6. GaneshKumar, K., Arivazhagan, D., (2016) New cryptography algorithm with for efficient data communication, Indian Journal of Science and Technology, 9(48), 108970.

7. Johnson, T. and Singh, S.K., (2015). K-strange points clustering algorithm. In Computational Intelligence in Data MiningVolume 1 (pp. 415-425). Springer India.

8. Archana, J. and Anita, E.M., (2015) A survey of big data analytics in healthcare and government. Procedia Computer Science, 50, pp.408-413.

9. Reid, J., \&Macnae, J. (2000). Current channelling in time-domain airborne electromagnetic data. Exploration Geophysics, 31(2), 150-157.

10. B. Thangalakshmi, (Nov 2013) Energy Detection Based Spectrum Sensing in Cognitive Radio Network, IJMSR, Vol.5, No.1.

11. Nils-Olav Skeie, Saba Mylvaganam and Bernt Lie. (2006) Using multi-sensor data fusion for level estimation in a separator. $16^{\text {th }}$ European Symposium on Computer Aided Process Engineering and 9th International Symposium on Process System Engineering W. Marquardt, C. Pantelides (Editors). Elsevier B.V. 1383-1388.

12. Ken-ichino SVEHARA. (2006) Development of an Air-oil and Oil-Water Interface Detector Using Plastic Optical Fiber and Its Application for Measurement of Oil Layer Thickness of Industrial Kitchen Wastewater in a Grease Trap. Journal of Chemical Engineering of Japan, (6): 670-677.

13. Ramon Casanella. Oscar Casas and Ramon Pallas-Aren. (2006) Oil-water interface level sensor based on an electrode array. IEEE instrumentation and measurement technology conference proceedings,:710-713.

14. SUN Punan. (2003) Development and application of YSJ-1 type oil-water interface level gauge. Nuclear technology, (8): 641- 
644.

15. M. Meribout, M. Habli, A. AI-Naamany and K. AI-Busaidi. (2004) A new ultrasonic-based device for accurate measurement of oil, emulsion, and water levels in the oil tank. In Proc. of the 21st IEEE Instrumentation and Measurement Technology Conference, IMTC 04, Como,:1942-1947. 